\title{
“Two-Level, Three-Field, and Four-Section” System: Expansion of Entrepreneurship Education for College and University Students
}

\author{
Hou Li-li \\ Shandong Jiaotong University, Jinan, China
}

\author{
Wang Lian-sen \\ Shandong University, Jinan, China
}

\begin{abstract}
On account of shortcomings in current entrepreneurship education for college and university students, new fields of "creation of a cause" and "starting of a business" are innovatively proposed, expanding the previous entrepreneurship field which is limited to "establishment of an enterprise"; construction of an entrepreneurship education chain containing "atmosphere section", "course section", "experience section", and "action section" is proposed, making entrepreneurship education more complete, more systematic, and deeper; and construction of entrepreneurship education platform at university and provincial levels which links up with each other and shares resources is proposed.
\end{abstract}

Keywords: entrepreneurship education, entrepreneurship, innovation

\section{Introduction}

Entrepreneurship is an exploratory behavior to make innovations in the fields of society, economy, culture, and politics in order to develop or expand new development space and offer opportunities to others and the society $(\mathrm{Xi}, 2008)$. Entrepreneurship education is an activity to cultivate entrepreneurial talents with entrepreneurial consciousness, entrepreneurial quality, entrepreneurial knowledge, and entrepreneurial capability. It aims at training individuals with entrepreneurial traits, for example, independence, creativity, capability to seek opportunities, and courage to take risks, and enabling them to adapt to the need of the future society. It shall be an important responsibility of higher education institutions to further develop entrepreneurship education on the existing basis from aspects of educational content, form, and conditions and train a great many entrepreneurial talents so as to offer steady human resource for vitality and sustainable development of national economy and all-round social progress.

\section{Expansion of Content of Entrepreneurship Education}

Entrepreneurship is a process to take opportunities to create value through bringing together a broad range of resources (Stevenson, Roberts, \& Grousbeck, 1999). Fundamentally speaking, it is a kind of creative behavior of human being (Michael \& Donald, 2005) and "is a way to think, reason, and act" (Zhang, Q. W. Li,

\footnotetext{
* Acknowledgement: This research was financially supported by the Independent Innovation Foundation of Shandong University (Grant No. IFW12116).

Hou Li-li, M.A., assistant lecturer, Library, Shandong Jiaotong University.

Wang Lian-sen, Ph.D., associate professor, Research Center for Higher Education, Shandong University.
} 
\& J. L. Li, 2006). "With the essence of innovation, entrepreneurship has become one of basic starting points to think things under new economic conditions in the new century, and entrepreneurial spirit has been a concept beginning to infiltrate all aspects of the society" (Zhang, Li, \& Chen, 2004). Nowadays, beyond the traditional concept to establish an enterprise, entrepreneurship has included the level of companies and organizations of different forms in various stages (Timmons, 2005).

In view of the above, entrepreneurship should not be limited to "establish a new enterprise" and shall be expanded. In this paper, new entrepreneurship fields are proposed, including "establishment of an enterprise" (establishment of a new profit-making organization), "creation of a cause" (origination of a new non-profit organization), and "starting of a business" (entrepreneurship inside the organization, not only including partial innovation in the original organization - new application of products/services (exploiting new market), improvement of products/services (research and development of new technologies), and creation of new products/services (development of new projects), but including overall innovation in the original organization - total transformation or relocation of operation businesses or organization reconstruction) (as shown in Figure 1).

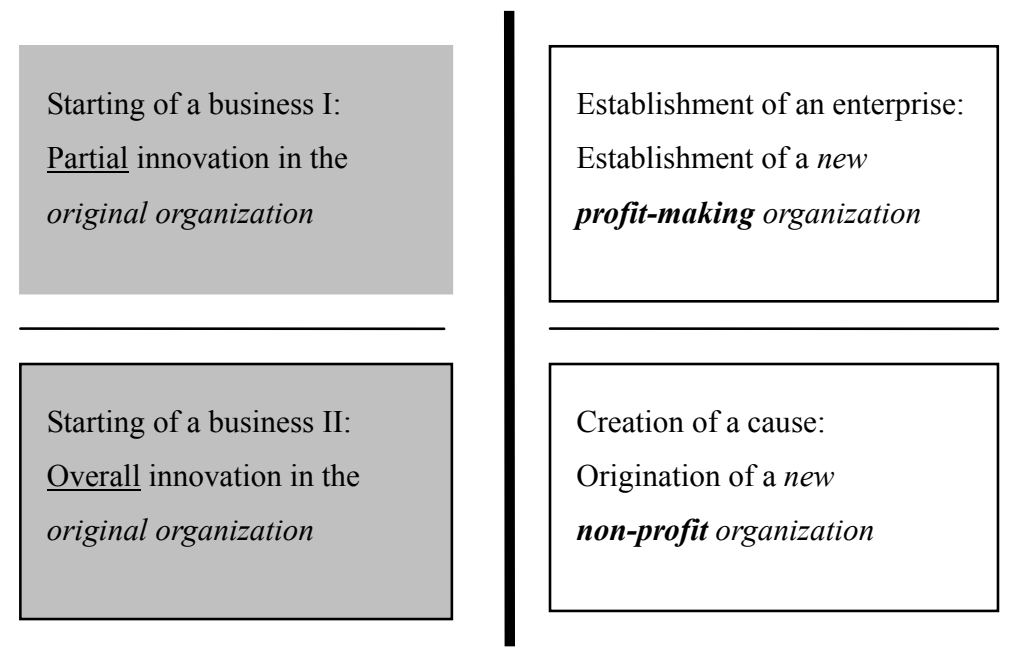

Figure 1. Expansion of "entrepreneurship" fields.

Three fields of "establishment of an enterprise", "creation of a cause", and "starting of a business" are common at fundamental level, that is, in discovering and capturing the opportunity and thus creating novel products or services and realizing their potential value. However, they are slightly different. "Establishment of an enterprise" is to establish a profit-making organization while "creation of a cause" is to set up a non-profit organization (school, hospital, association, charitable organization, etc.). Non-profit organizations are important social organizations other than enterprises with operation objectives and methods different from enterprises and are called as one of three major sectors in the society. "Establishment of an enterprise" and "creation of a cause" are to start an undertaking through establishing a new organization, that is, "zero-organizational entrepreneurship", while "starting of a business" is to develop new businesses in or based on the existing organization and is "intra-organizational entrepreneurship". Based on expanded entrepreneurship fields, entrepreneurship education should not be limited to cultivating talents that can establish enterprises and shall be expanded accordingly - to train persons who are willing to and can start a business or even establish an enterprise or create a cause. Such persons are initiative and have the entrepreneurial capability. 
Entrepreneurship education shall be executed according to different types of colleges and universities. "Higher vocational colleges shall focus on skilled necessity entrepreneurship education, ordinary teaching universities on creative developing entrepreneurship education, and research-oriented universities on innovative and leading entrepreneurship education" (Xi, 2008). This suggests us taking full account of the matching relationship between "innovativeness" of "an enterprise", "a cause", and "a business" and complexity while starting them and receptivity and development directions of educational objects so as to "teach students in accordance with their aptitude".

It would be specially mentioned that being "social entrepreneurship", "creation of a cause" lays stress on social objectives and public benefits of entrepreneurship and boycotts and contends against "utilitarianism", "mammonism", and "hedonism", being significantly valuable to economic and social development and the progress of human civilization; while "starting of a business" is to develop new businesses in or based on the existing organization and is "intra-organizational entrepreneurship", but not starting from scratch, which has realistic operability for newly graduated college and university students. Therefore, it is important to provide guidance and advice to college and university students and support them in "establishment of an enterprise", and it is equally important in "creation of a cause" and "starting of a business", especially under the current condition ignoring the later two fields.

\section{Expansion of Forms of Entrepreneurship Education}

The Entrepreneurship Education Alliance of the United States (U.S.) considers that as a lifetime study process, entrepreneurship contains at least fundamental cognition, ability and competence, innovation training, entrepreneurial practice, and entrepreneurial development stages (Ashmore, n.d.). It is clear that entrepreneurship education intended to "train persons who are willing and able to start a business or even establish an enterprise and create a cause" must be integrated and systematic. Traditional entrepreneurship education still pauses in simple and single forms, such as "course teaching" and "entrepreneurial plan competition activities". It shall be expanded to build up an entrepreneurship education chain comprised of "atmosphere section", "course section", "experience section", and "action section". Through multiple consistent and progressive educational methods and approaches from perception to rationality, from easy to difficult, and applying theory to practice and increasing both knowledge and capability, the expanded entrepreneurship education chain can train and shape entrepreneurial talents with entrepreneurial consciousness (strong entrepreneuriall spirit and sense of social responsibility, high confidence, innovative spirit, and rational adventurous spirit), entrepreneurial quality (with passion, permanent ambition, courage to undertake the responsibilities and break the routine, good skills of communication and difficulty resolution, active thinking, unique ideas, and capability to handle matters flexibly), entrepreneurial knowledge (enterprise/cause/business preparation stage, enterprise/cause/business establishment stage, enterprise/cause/business development, and enterprise/cause/business maturity), and entrepreneurial capability (capability to collect, analyze, and judge information, capability to identify and seize the opportunity, capability to make decisions and put into practice, and leadership ability of innovative and creative resource integration, team building, and excellent balance).

"Atmosphere section" aims at stimulating entrepreneurial consciousness of students through propaganda and mobilization, specialist reports, entrepreneurship forums, etc., to make them touch, perceive, and understand entrepreneurship and then identify, advocate, and aspire to entrepreneurship.

"Course section" aims at offering courses to impart entrepreneurial knowledge and shape entrepreneurial 
quality. For instance, entrepreneurial philosophy, entrepreneurial ethics, entrepreneurial psychology, entrepreneurial economics, entrepreneurial management, entrepreneurial environmental studies, entrepreneurial talentics, science of entrepreneurial law, entrepreneurial design studies, entrepreneurial practice courses, etc., can be offered for teaching of "establishment of an enterprise" (Xi, 2008). "Entrepreneurship" is strongly practical knowledge. More practice-oriented courses, such as entrepreneur lectures (to introduce their experiences and sense of achievement in entrepreneurship and impart their own opinions on some problems, mainly practice-based summary), entrepreneur fellowship (to invite principals from successful entrepreneurial alumni, entrepreneurial investment companies, and enterprise parks and experts in entrepreneurship education as honored guests), case study (analysis and discussion specific to some individual successful/unsuccessful entrepreneurship cases), course seminars (to study the content of the course in the form of seminars, for example, discussion on "Why to promote the entrepreneurial spirit" and "What kind of persons can become entrepreneurs", so as to deepen understanding of the entrepreneurial spirit and quality), "brain storms" (to form some realistic and operable business ideas) (Y. K. Zhang, X. H. Zhang, \& Cao, 2009) etc., shall be offered. Construction of research, discussion, project, and self-learning courses shall be strengthened to provide more opportunities for the students to participate in the teaching process and promote the students to think actively. It can be explored to penetrate entrepreneurship education into the main channel of professional teaching to promote deeper integration of entrepreneurship education and professional education, for instance, to open professional entrepreneurship practice course so as to specifically offer education of innovation and entrepreneurship in some an industry and some a field to the students.

"Entrepreneurial capability ... cannot be cultivated in class and it is required to go to the society and study it in social practices" (Gu, 2002). "Experience section" lays stress on "practice" and aims at promoting the students to study in interaction, action, and reflection through role modeling, computer simulation operation, site observation, probation in the base, temporary position internship, entrepreneurship design competition, entrepreneurial elite training camp, etc., and further simulating entrepreneurial consciousness of the students, digesting and absorbing entrepreneurial knowledge, especially studying and advancing their "tacit knowledge" (Chai, 2010), improving their entrepreneurial capability and shaping their entrepreneurial quality through the above practical activities. This section can especially strengthen experiments and practice teaching in links of "market research, opportunity analysis, project design, business model formulation and selection, program planning, project implementation, and marketing" inevitably involved in entrepreneurship with the aid of computer means. Besides, assessment on this section shall focus on team assessment and be supplemented by individual assessment; lay stress on "simulation entrepreneurship practice" and see it as the most important part in the team performance; and give the assessment right of every student's performance to themselves.

"Action section" is to absorb and support the students to actually undertake entrepreneurship by setting up platforms similar to "college and university student entrepreneurship street", "professional entrepreneurship studio", "teacher and student entrepreneurship studio", entrepreneurship parks, and incubation bases so as to digest, absorb, study, and promote entrepreneurial knowledge, improve entrepreneurial capability, and shape entrepreneurial quality until real achievement of entrepreneurship.

Various sections shall face different student populations. "Atmosphere section" can face all students. "Course section" and "experience section" can either be independent or combined with each other to let the students participate in forms of required or elective course and minor, double-degree even or major program. 
"Action section" is only appropriate for those entrepreneurial trained students with true entrepreneurial intentions and entrepreneurial potential.

\section{Expansion of Conditions of Entrepreneurship Education}

Implementation of any education must rely on certain conditions, especially implementation of entrepreneurship education involving the above three fields and four sections with strong integrity and high level of systematization, which must be supported by a solid and powerful platform. For colleges and universities, entrepreneurship education shall be to actively get support from various aspects, strengthen union with other colleges and universities, and apply educational resources sufficiently in various channels. Superior responsible departments, for instance, provincial responsible departments, shall attach great importance to strongly supporting and arranging comprehensively entrepreneurship education for college and university students in the local area. In a word, university-level and provincial (or regional) entrepreneurship education platforms shall be designed integrally and established powerfully from aspects of institution, personnel, funds, bases, information, systems, policies, and culture to establish a long-effect mechanism to implement entrepreneurship education and construct entrepreneurship education ecological systems in the whole campus and in the whole region.

First of all, to establish two-level entrepreneurship education platforms is to set up special institutions for entrepreneurship education. At college or university level, a university leadership or coordination organization for development of entrepreneurship education shall be established to integrate entrepreneurship education resources in different departments, such as teaching affairs office, school of economics or management, student affairs office, enrollment and employment office, Youth League Committee, scientific research office, logistics office, science park, etc.. At provincial level, special leadership, management, or service organization shall be established to organize implementation of entrepreneurship education in the region. Jiangxi Entrepreneurship Research and Guidance Center for Colleges and Universities is an organization established in Jiangxi Province to assist the department in charge of higher education in this province in promoting work of entrepreneurship education. Its specific responsibilities include: to make planning about entrepreneurship education for colleges and universities in the whole province and give development proposals; to promote basic construction of entrepreneurship education, for example, teaching staff team building, teaching material construction, etc.; to organize and develop academic exchange activities on entrepreneurship education; to plan and organize entrepreneurship education and entrepreneurial activities for college and university students; to explore construction of entrepreneurship investment systems and entrepreneurship incubation bases for university students so as to promote transformation of entrepreneurial achievements; to provide specific guidance on entrepreneurship education in colleges and universities; to create a sound environment for entrepreneurship education to strive for support from various aspects in entrepreneurship education; to integrate the work of entrepreneurship education in colleges and universities in the whole province and summarize experiences of entrepreneurship education; etc..

Besides close connection between provincial and university-level platforms, all colleges and universities in the region shall enhance communication and cooperation and construct an "entrepreneurship education cooperation community". "Various entrepreneurship education institutions can obtain optimum educational effectiveness only by forming a linkage mechanism" (Mei \& Xu, 2009). Inter-university cooperation exists extensively in entrepreneurship education in American universities, facilitating exchange and sharing of 
educational resources, typically "establishment of partnership between Babson School of Business, a pioneer in entrepreneurship education in the U.S., and Olin College of Engineering, a famous engineering college which integrates entrepreneurship education in engineering courses” and “'Global Entrepreneurship Monitor' (GEM) jointly undertaken by Babson School of Business and London Business School”.

Many examples of the U.S. entrepreneurship education cooperation prove that compared with the single system, multi-stage linkage has distinct advantages, for instance, cooperation can enrich faculties of entrepreneurship education, increase funds for entrepreneurship education, create the atmosphere of entrepreneurship education, etc.. (Huang, Zeng, \& Shi, 2010)

\section{Conclusion}

In conclusion, this paper advocates expansion of entrepreneurship education from the educational content, i.e., "what to teach", the educational form, i.e., "how to teach", and the educational conditions, i.e., "be able to teach". In the content, it advocates expansion from "establishment of an enterprise" to three entrepreneurship fields: "establishment of an enterprise", "creation of a cause", and "starting of a business"; in the form, expansion from "course teaching" and "entrepreneurial plan competition" to an entrepreneurship education chain comprised of "atmosphere section", "course section", "experience section", and "action section"; and in the conditions, expansion from "single entrepreneurship" of colleges and universities to the establishment of university-level and provincial entrepreneurship education platforms and final construction of a "two-level, three-field, and four-section" entrepreneurship education system for college and university students (as shown in Figure 2).

Different from fragmental, scattered, and isolated entrepreneurship education theory and its practice, the "two-level, three-field, and four-section" entrepreneurship education system is an open, organic, and complicated education system with multiple levels and multiple factors which coordinates up and down and echoes left and right. It can achieve consistent coordination of managerial behaviors, teaching behaviors, and learning behaviors in entrepreneurship education, favorable to extensive, deep, and sufficient development of entrepreneurship education and achievement of comprehensive targets of entrepreneurship education for college and university students with entrepreneurial consciousness, entrepreneurial quality, entrepreneurial knowledge, and entrepreneurial capability in one. It is suitable for colleges and universities of all levels and various types to adopt to develop systematic and comprehensive entrepreneurship education according to their own characteristics. It can be provided for responsible governmental organizations to organize and implement entrepreneurship education for college and university students in each province and can be also provided for those teaching and research staffs engaged in entrepreneurial studies and entrepreneurship education for reference.

The above only gives necessity and basic idea of expansion of entrepreneurship education. More detailed and deeper research shall be developed by comprehensively using methods of literature survey, classification and summarization, historical method and comparative method, field research, and case study from the following aspects (Wang \& Dong, 2010):

1. Study on "three fields": study on content, objectives, process, approaches, methods, and quality requirements for entrepreneurs of "establishment of an enterprise" (mainly reference to management theory and methods of the enterprise); study on content, objectives, process, approaches, methods, and quality requirements for entrepreneurs of "creation of a cause" (mainly reference to management theory and methods 
of the non-profit organization); and study on content, objectives, process, approaches, methods, and quality requirements for entrepreneurs of "starting of a business" (mainly reference to project management theory and methods).

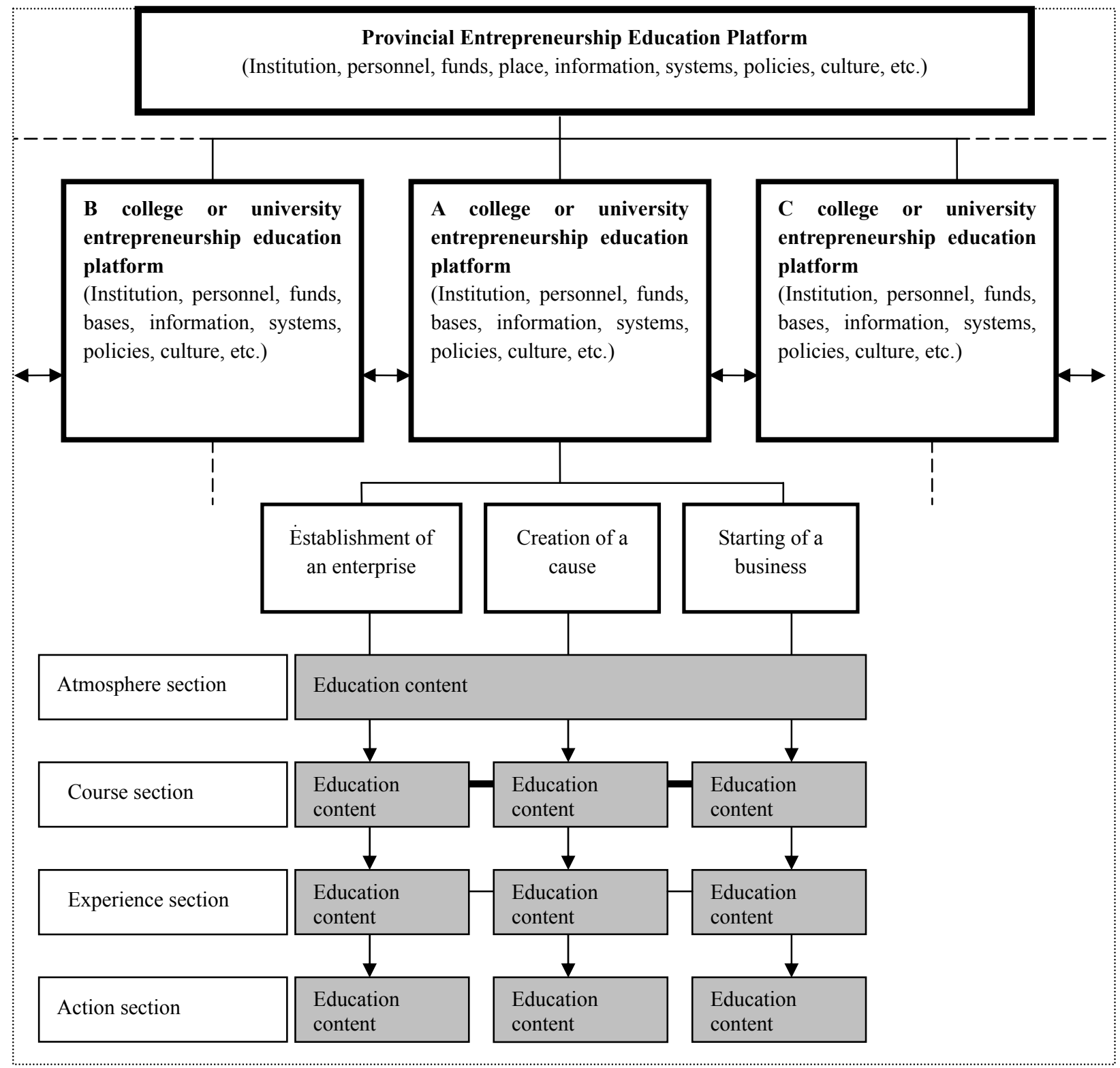

Figure 2. "Two-level, three-field, and four-section" entrepreneurship education for college and university students.

2. Study on "four sections": the direction, degree, and applicability of educational objectives, i.e., objectives in entrepreneurial consciousness, entrepreneurial quality, entrepreneurial knowledge, and entrepreneurial capability of "atmosphere section", "course section", "experience section", and "action section", educational approaches, ways and methods of the above four sections, and applicability adjustment of common educational objectives and educational approaches, and ways and methods of each of the four sections in colleges and universities of different levels and types (research, teaching, and higher vocational types).

3. Study on "two levels": support, guarantee, and assessment systems of university-level "three-field and 
four-section" entrepreneurship education platform (institution, personnel, funds, bases, information, systems, policies, culture, etc.), and support, guarantee, and assessment systems of provincial "three-field and four-section" entrepreneurship education platform (institution, personnel, funds, bases, information, systems, policies, culture, etc.).

4. Comprehensive study on "two levels, three fields, and four sections": difference and connection among three fields "establishment of an enterprise", "creation of a cause", and "starting of a business", continuality among "atmosphere section", "course section", "experience section", and "action section", and linkage between university-level and provincial entrepreneurship education platforms.

\section{References}

Ashmore, C. (n.d.). Five stages of lifelong learning. Retrieved February 15, 2010, from http://www.entre-ed.org/_ entre/5-stages.htm

Chai, X. D. (2010). Entrepreneurship education for colleges and universities within the scope of tacit knowledge. Higher Engineering Education Research, 1, 75-80.

Gu, M. Y. (2002). Colleges and universities shall offer entrepreneurship education to the students. China University Teaching, 10, 16.

Huang, Z. X., Zeng, E. L., \& Shi, Y. C. (2010). Cooperation in entrepreneurship education in USA: Concept, modes and their inspiration. Research in Higher Education, 4, 107-109.

Mei, W. H., \& Xu, X. Z. (2009). Development difficulties and strategies in entrepreneurship education for colleges and universities in China. Education Studies, 4, 70.

Michael, H. M., \& Donald, F. K. (2005). Corporate entrepreneurship: Intra-organizational entrepreneurship development. Beijing: Tsinghua University Press.

Stevenson, H. H., Roberts, M. J., Grousbeck, D. E. (1999). New business ventures and entrepreneur. Homewood: Richard D. Irwin.

Timmons, J. A. (2005). New venture creation (6th ed.). Beijing: Posts \& Telecom Press.

Wang, L. S., \& Dong, L. P. (2010). Design idea of "two-level, three-field, and four-section" entrepreneurship education platform. Education Exploration, 8, 132.

Xi, S. Y. (2008). Concept, idea and practice of entrepreneurship education for colleges and universities in China. Beijing: Science Press.

Zhang, Y. K., Zhang, X. H., \& Cao, T. (2009). Training of entrepreneurial capability in practice teaching of the course of management. China University Teaching, 6, 53.

Zhang, Y. L., Li, Q. W., \& Chen, H. S. (2004). Latest review and research trend of entrepreneurial management theory. Forecasting, 4, 21.

Zhang, Y. L., Li, Q. W., \& Li, J. L. (2006). Review of new ideas about studies on entrepreneurial management. Foreign Economics and Management, 5, 1. 